\title{
The polyamine spermine induces cystocarp development in the seaweed Grateloupia (Rhodophyta)
}

\author{
Alicia T. Sacramento · Pilar García-Jiménez • \\ Rafael R. Robaina
}

Received: 23 May 2007 / Accepted: 24 July 2007/Published online: 12 August 2007

(C) Springer Science+Business Media B.V. 2007

\begin{abstract}
Polyamines such as putrescine, spermidine and spermine are ubiquitous aliphatic amines involved in reproductive events in plants and algae, and first become evident through changes in endogenous levels during reproductive development. To examine whether the differences observed in polyamines, during carposporogenesis, in the red alga Grateloupia, followed a specific pattern as is seen in other organisms, infertile axes (i.e. not showing cystocarps) were excised from the same holdfast of female fertilized individuals (i.e. showing cystocarps in other axes), and cultivated until the cystocarps became visible. Changes in the endogenous levels of free putrescine, spermidine and spermine were monitored over the 8 days of culture. The activity of enzymes related to polyamine metabolism, such as L-ornithine decarboxylase (ODC), diamine oxidase and polyamine oxidase, was measured at the beginning and end of the experimental period. Up to $50 \%$ of the infertile axes became fertile and produced cystocarps at a density of $1.91 \pm 0.1$ cystocarps $\mathrm{mm}^{-2}$ after 8 days. The endogenous content of spermine increased markedly over the first 5 days of culture, then decreased to the initial level by day 8 .
\end{abstract}

A. T. Sacramento · P. García-Jiménez .

R. R. Robaina $(\square)$

Departamento de Biología, Universidad de Las Palmas

de Gran Canaria, Campus Universitario de Tafira,

C.P. 35017 Las Palmas de Gran Canaria, Spain

e-mail: rrobaina@dbio.ulpgc.es
Spermidine followed a similar pattern to spermine, whereas putrescine remained at high levels, until day 5 when it decreased abruptly. The activity of ODC was less on day 8 than on day 0 , whereas the activities of diamine oxidase and polyamine oxidase increased. In parallel experiments with explants from infertile axes, exogenously added spermine $\left(10^{-6} \mathrm{M}\right)$ increased the number of cystocarps, and reversed the effect of cyclohexylamine (CHA), which is known to inhibit polyamine synthesis in Grateloupia. Serial sectioning and microscopic observation of specimens from explants cultivated in $10^{-6} \mathrm{M}$ spermine indicated that cystocarp development was induced. The results suggest that, during transition from infertile to fertile spermine is accumulated, thus favouring the development of cystocarps, given the presumed role of spermine as an inducing agent.

Keywords Cystocarp development . Enzymes · Grateloupia · Polyamines · Red macroalga $\cdot$ Spermine

\section{Introduction}

The polyamines putrescine, spermidine and spermine are aliphatic amines with a relatively low-molecular mass, which are known to modulate a variety of physiological processes in higher plants (Flores 1990; Galston et al. 1997; Kakkar and Kaur-Sawhney 2002). In algae, there are data on the endogenous 
levels of polyamines in several green, red and brown algae (Badini et al. 1994; Marián et al. 2000a). These polyamines are involved in cell division (Cohen et al. 1984; García-Jiménez et al. 1998; Marián et al. 2000b; Voigt et al. 2000; Theiss et al. 2002), and in response to hyposaline stress (Lee 1998; GarcíaJiménez et al. 2007).

Recent evidence also supports the involvement of polyamines in the reproduction of marine multicellular algae. Guzmán-Urióstegui et al. (2002) and Sacramento et al. (2004) noted that the endogenous levels of polyamines decreased in the transition from the infertile to the fertile state in Gracilaria cornea and Grateloupia sp., respectively. They also observed that spermine promoted the liberation and growth of spores from cultivated explants in both species of red algae. Sacramento et al. (2004) reported the occurrence of both L-ornithine decarboxylase (ODC, EC. 4.1.1.17) and L-arginine decarboxylase (ADC, EC. 4.1.1.19) in Grateloupia. However, it was ODC activity which correlated more closely to the levels of polyamines detected in collected fertile and infertile thalli. The synthesis of polyamines starts with putrescine, which is predominantly synthesized by the key enzyme ODC (although putrescine can also be synthesized by the decarboxylation of L-arginine in plants and algae). The decarboxylated S-adenosylmethionine (dSAM) obtained from S-adenosylmethionine (SAM) provides aminopropyl moieties which convert putrescine into spermidine, and then into spermine. The polyamines thereby produced may be degraded by diamine oxidases (DAO, EC. 1.4.3.6) and polyamine oxidases (PAO, EC. 1.4.3.4).

On the basis of the previously observed differences between the collections of infertile and fertile carposporophytic thalli in the endogenous polyamines and enzymes, and the effect of spermine on sporulation observed in Grateloupia (Sacramento et al. 2004) this work attempts to establish the basis of the differences in the polyamines between collected infertile and fertile samples: if they represent a simple and progressive decrease (i.e. by polyamine excretion, degradation or lack of production), or are rather the result of specific and abrupt changes which may have morphogenetic consequences at other stages of the reproductive process, such as occurs in other organisms (e.g. to maintain constant levels or a sharp decrease of spermine to determine, respectively, ovary senescence or parthenocarpy in tomato
(Galston et al. 1997; Fos et al. 2003). In order to do this, infertile axes (i.e. not showing cystocarps) were excised from the same holdfast of fertilized individuals, and cultivated until they developed cystocarps. The changes in the polyamine levels were monitored throughout cystocarp development, as was the activity of enzymes related to the polyamine metabolism, such as ODC, DAO and PAO. Inhibitors of polyamine synthesis and light microscopy was used to provide further evidence for the apparently inductive effect of spermine on cystocarp development.

\section{Materials and methods}

Plant material and culture conditions

Grateloupia sp. (Halymeniaceae, Rhodophyta) is an intertidal red alga found along the North-East coast of Gran Canaria, Canary Islands, Spain. Formerly assigned to $G$. doryphora, its taxonomic position is now being revised (Gavio and Fredericq 2002). A voucher specimen of the species used in this and previous work was deposited as sheet 6100 in the BCM herbarium (Biology Dept., University of Las Palmas de Gran Canaria, Canary Islands). In members of the Halymeniaceae, such as Grateloupia, the cystocarps appear in the female gametophyte as small, dark spots $(<1 \mathrm{~mm}$ in diameter), completely embedded in the thalli, and can be identified under the stereomicroscope in naturally collected samples. Thus, infertile and fertile axes belonging to the same individual (i.e. anchored to the same basal structure) are easily distinguished. Within $2 \mathrm{~h}$ of collection, the infertile axes were identified, separated and used to monitor cystocarp development.

Infertile axes (ca. $20 \mathrm{~g} \mathrm{FW}$ ) were cultured for 8 days in 301 aerated glass tanks with 201 of Provasoli Enriched Seawater medium (PES, Provasoli 1968). The nutrients and seawater were replenished every 5 days throughout the experiment. The cultures were maintained at $20 \pm 2^{\circ} \mathrm{C}$ and $30 \mu \mathrm{mol}$ photons $\mathrm{m}^{-2} \mathrm{~s}^{-1}$ in a growth chamber. As cultures progressed, thalli were separated into those that were still infertile, and those that were fertile, and then weighed to monitor the increase of fertile thalli, expressed as a percentage of the total weight of thalli. The experiment was repeated three times. The density of cystocarps per $\mathrm{mm}^{2}$ was determined at day 
8 on $4 \mathrm{~mm}$ diameter explants, excised from the zone where most cystocarp spots were observed within the thalli ( $n=55$ explants). Based on the pattern of transition from infertile to fertile axes, the culture was repeated and on days $0,2,5$ and 8 , two or three randomized samples of axes (regardless of whether they were fertile or infertile) were withdrawn from the glass tank, and then frozen in liquid $\mathrm{N}_{2}$ and stored at $-80^{\circ} \mathrm{C}$ until used to determine PA contents.

Structural evidence relating to the effect of spermine was sought using explants of infertile axes (discs of $3 \mathrm{~mm}$ diameter, $n=24$ discs) which were surface sterilized and cultivated for 7 days in 2-ml multiwell plates (Sigma Inc., Deisenhofen, Germany) with $1 \mathrm{ml}$ of filter sterilized PES medium or PES + $10^{-6} \mathrm{M}$ spermine. Each day, two explants were removed and fixed, sectioned to obtain serial sections, and stained as previously described (García-Jiménez et al. 1998; Guzmán-Urióstegui et al. 2002). In a parallel experiment, the number of cystocarps per $\mathrm{mm}^{2}$ was recorded at the end of the experiment (7 days) to check the inductive effect of spermine, as compared to cyclohexylamine (CHA, Sigma-Aldrich C-6380), dicyclohexylamine (DCHA, Sigma-Aldrich cat no. 18,584-1), CHA + spermine and DCHA + spermine (all at $10^{-6} \mathrm{M}, n=8$ disc explants per treatment). CHA and DCHA inhibit synthesis of polyamines at the level of putrescine synthesis in Grateloupia (Sacramento et al. 2004) although, as reported in Kakkar and Kaur-Sawhney (2002) and Wallace et al. (2004), hexylamine derivatives are also expected to inhibit spermidine or spermine synthases.

Extraction and dansylation of free polyamines for HPLC

The polyamines were extracted with $5 \%$ cold perchloric acid in a 1:10 ratio of material ( $\mathrm{g}$ fresh weight : ml). The supernatants, obtained by centrifugation $\left(5,000 \mathrm{~g}, 20 \mathrm{~min}\right.$ at $\left.4^{\circ} \mathrm{C}\right)$ in a bench top refrigerated centrifuge containing the acid soluble free fraction, were dansylated and quantified by HPLC, using the method described by Marcé et al. (1995). Polyamine losses during extraction and dansylation were corrected using 1,7 diaminoheptane (Aldrich) as an external standard, which was added to all samples at $6.6 \mu \mathrm{M}$ final concentration.
Enzyme activity analysis

New cultures of infertile axes were used to determine enzymatic activities on days 0 and 8 . The samples (ca. $20 \mathrm{~g} \mathrm{FW}, n=2-4$ ) were ground in a mortar with liquid $\mathrm{N}_{2}$, and the proteins were extracted in a phosphate buffer (70 mM, pH 7.5) containing $10 \mathrm{mM}$ DL-dithiothreitol $0.3 \mathrm{mM}$ pyridoxal phosphate and $1 \mathrm{mM}$ phenylmethyl sulphonyl fluoride. The slurry was centrifuged $\left(5,000 \mathrm{~g}, 4 \mathrm{~min}, 4^{\circ} \mathrm{C}\right)$, the pellet was discarded and the supernatant $(0.3-0.6 \mathrm{mg}$ proteins $\mathrm{ml}^{-1}$ ) was used for the enzyme activity assays. Protein concentration in the crude extract was determined using the DTT compatible RCDC BioRad, Hercules, CA, USA, protein determination kit, which eliminated the possibility of DTT interference. Bovine serum albumin was used as a standard.

The ODC activity was assayed in Warburg respirometer vessels containing $0.3 \mu \mathrm{Ci}$ of $\mathrm{L}-\left[1-{ }^{14} \mathrm{C}\right]$ ornithine $\left(52 \mathrm{mCi} \mathrm{mmol}^{-1}\right.$, Amersham Biosciences, Buckinghamshire, UK), and L-ornithine $(0.7 \mathrm{mM}$ total L-ornithine in the reaction mixture) in $250 \mu \mathrm{l}$ crude extract for $60 \mathrm{~min}$. The ${ }^{14} \mathrm{CO}_{2}$ released as a result of decarboxylase activity was trapped over $60 \mathrm{~min}$ by agitation with $100 \mu \mathrm{l}$ Solvable trapping solution (NEN, UK) and counted using Formula 989 (NEN) as a scintillant. Extracts denatured by heating $\left(150^{\circ} \mathrm{C}, 30 \mathrm{~min}\right)$ was used as controls.

The determination of diamine oxidase activity was carried out with $500 \mu \mathrm{l}$ of extract supernatant, $0.1 \mathrm{M}$ unlabelled putrescine, $0.5 \mu \mathrm{Ci}$ of $\left[\mathrm{U}_{-}{ }^{14} \mathrm{C}\right]$-putrescine (107 $\mathrm{mCi} \mathrm{mmol}^{-1}$ ) made up to $1 \mathrm{ml}$ with phosphate buffer $(70 \mathrm{mM}, \mathrm{pH}$ 7.3). Following preliminary experiments, the extracts were pre-activated with $10 \mu \mathrm{CuSO}_{4}(100 \mu \mathrm{M})$ for $10 \mathrm{~min}$ at $37^{\circ} \mathrm{C}$ before the addition of putrescine substrate. Thereafter, the enzymatic reaction was carried out at $37^{\circ} \mathrm{C}$ in a water bath, with constant shaking for $30 \mathrm{~min}$, and halted by adding $1 \mathrm{ml} 4 \mathrm{~N} \mathrm{NaOH}$ and vortexing for $30 \mathrm{~s}$ to encourage spontaneous cyclization of aminobutyraldehyde to pyrroline. Radioactive pyrroline was extracted in $2 \mathrm{ml}$ toluene by vortexing, and counted as previously described. Extracts denatured by heating $\left(150^{\circ} \mathrm{C}, 30 \mathrm{~min}\right)$ were used as controls.

Polyamine oxidases are flavoproteins responsible for the degradation of spermidine and spermine into pyrroline, diaminepropane and $\mathrm{H}_{2} \mathrm{O}_{2}$. As with DAO, therefore, we quantified the radioactive pyrroline produced from $\left[\mathrm{U}_{-}{ }^{14} \mathrm{C}\right]$-spermidine $\left(112 \mathrm{mCi} \mathrm{mmol}^{-1}\right)$. 
The enzyme assay was performed using $0.1 \mathrm{M}$ unlabelled spermidine and $0.49 \mu \mathrm{Ci}\left[\mathrm{U}_{-}{ }^{14} \mathrm{C}\right]$-spermidine as substrates in $70 \mathrm{mM} \mathrm{K}$-phosphate buffer $(\mathrm{pH}$ 6.0). The samples $(500 \mu \mathrm{l}$ of crude extract) were preincubated for $10 \mathrm{~min}$ with $3 \mu \mathrm{l}$ of $10 \mathrm{mM}$ FAD (Sigma Co.), prior to the addition of spermidine substrate and phosphate buffer to a final volume of $1 \mathrm{ml}$. Thereafter, the enzymatic reaction was carried out at $37^{\circ} \mathrm{C}$ in a water bath, with constant shaking for $30 \mathrm{~min}$, and stopped by the addition of $1 \mathrm{ml} 4 \mathrm{~N}$ $\mathrm{NaOH}$. The radioactive pyrroline was determined as described above. Extracts denatured by heating $\left(150^{\circ} \mathrm{C}, 30 \mathrm{~min}\right)$ were used as controls.

\section{Results}

The infertile axes excised from fertilized individuals became fertile, and developed conspicuous cystocarp spots on the thalli (Table 1). The cystocarp development was not abrupt but became conspicuous by day 2 , and then progressed to reach a maximum on day 8 . The weight of fertile axes increased from 0 to around $50 \%$ of the total cultivated biomass after 8 days. The analysis of the number of cystocarps revealed that the density of spots on $4 \mathrm{~mm}$ diameter explants reached $1.91 \pm 0.1 \mathrm{~mm}^{-2}$ (mean $\pm \mathrm{SE}$, range $\left.=0.63-3.98\right)$.

The endogenous content (Fig. 1) of spermine increased markedly over the first 5 days of culture, and then decreased to the initial level by day 8 , by which time maximum differentiation of cystocarps in infertile axes was always observed, as described above. The content of spermidine followed a similar pattern to spermine, whereas the putrescine remained high until day 5 then decreased sharply.
There were significant differences in the activity of all enzymes checked: ODC decreased to $30 \%$ of its initial activity from days 0 to 8 , DAO increased tenfold and polyamine oxidase increased more than 15-fold (Table 1).

The explants cultivated in PES $+10^{-6} \mathrm{M}$ spermine showed a higher density of cystocarps than the controls in PES alone (Table 2). CHA inhibited cystocarp development, but its effect was reversed by the addition of spermine. DCHA alone did not apparently affect cystocarp development, but explants cultivated in spermine + DCHA also showed a significantly higher density of cystocarps than in the control explants (Table 2).

Structural differences between explants cultivated in spermine and those cultivated without it were observed under light microscopy. It was possible to observe cystocarps proliferating at different stages of development in explants cultivated in spermine, as soon as 2 days. The differences between the treatments became even more apparent after 7 days, with greater differentiation of carpogonial branches in explants cultivated in spermine than in those in PES (Fig. 2a, b). The cystocarps developed in explants in spermine even extruded sometimes from the thalli.

\section{Discussion}

Carposporogenesis has been correlated with polyamine levels in the thalli in two rhodophytes to date. In G. cornea, Guzmán-Urióstegui et al. (2002) compared polyamines in collected samples over three clearly differentiated stages of cystoparp development: female without cystocarps, immature cystocarps as dark spots over the thalli, and mature

Table 1 Activities of enzymes involved in the metabolism of polyamines in thalli of Grateloupia after 8 days of cystocarp development

\begin{tabular}{|c|c|c|c|c|c|}
\hline & $\begin{array}{l}\text { Percentage of } \\
\text { fertile thalli }{ }^{\mathrm{a}}\end{array}$ & $\begin{array}{l}\text { Number of cystocarps, } \\
\mathrm{mm}^{-2}(n=55)\end{array}$ & $\begin{array}{l}\text { ODC } \\
\mathrm{pmol} \mathrm{h}^{-1} \mathrm{mg}^{-1}\end{array}$ & $\begin{array}{c}\text { DAO } \\
-1 \text { protein }(n=2-4)\end{array}$ & PAO \\
\hline Day 0 & None $^{\mathrm{b}}$ & None $^{b}$ & $2.5 \pm 1$ & $31 \pm 10$ & $7 \pm 3$ \\
\hline Day 8 & Up to $50 \%$ & $1.91 \pm 0.1$ & $0.74 \pm 0.04 *$ & $384 \pm 76^{*}$ & $120 \pm 18 *$ \\
\hline \multirow{2}{*}{\multicolumn{6}{|c|}{$\begin{array}{l}\text { ODC_L-ornithine decarboxylase }\left(\mathrm{pmol}^{14} \mathrm{CO}_{2} \mathrm{mg}^{-1} \text { protein } \mathrm{h}^{-1}\right) \text {, DAO_diamine oxidase }\left(\mathrm{pmol}{ }^{14} \mathrm{C} \text {-pyrroline } \mathrm{mg}^{-1} \mathrm{protein}^{-1}\right) \text {, } \\
\left.\text { PAO_-polyamine oxidase (pmol }{ }^{14} \mathrm{C} \text {-pyrroline } \mathrm{mg}^{-1} \text { protein } \mathrm{h}^{-1}\right) \\
\text { * Significant differences from day } 0 \text { at } p=0.05\end{array}$}} \\
\hline & & & & & \\
\hline \multicolumn{6}{|c|}{ a Weight of infertile axes that became fertile as percentage of total weight of thalli in culture } \\
\hline \multicolumn{6}{|c|}{ b Cystocarps not evident under stereomicroscope } \\
\hline
\end{tabular}




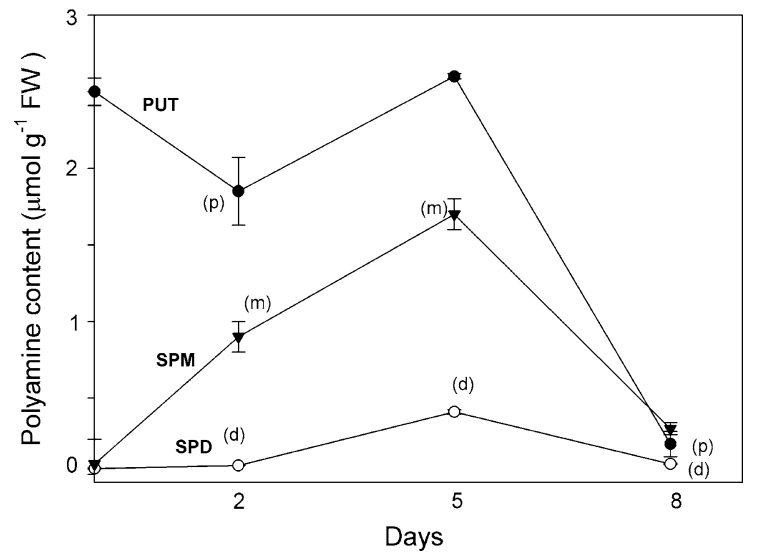

Fig. 1 Concentrations of endogenous polyamines during cystocarp maturation in Grateloupia. PUT-free putrescine (filled circle), SPD-spermidine (open circle), SPMspermine (inverted filled triangle). Data are mean concentrations of polyamines from samples retrieved from cultures at days $0,2,5(n=3)$ and $8(n=2)$. Based on Kruskal-Wallis tests, $(p)$ indicates a significant difference in putrescine from day 0 at $p=0.05 ;(d)$ a significant difference in spermidine from day 0 at $p=0.05$; and $(m)$ a significant difference in spermine from day 0 at $p=0.05$

Table 2 Cystocarp density in explants from fertilized thalli of Grateloupia cultivated for 7 days in the presence of spermine (SPM, $10^{-6} \mathrm{M}$ ) with or without inhibitors of polyamine synthesis, cyclohexylamine (CHA, $10^{-6} \mathrm{M}$ ) and dicyclohexylamine (DCHA, $10^{-6} \mathrm{M}$ )

\begin{tabular}{ll}
\hline & Number of cystocarps $\left(\mathrm{mm}^{-2}\right)$ \\
\hline Control & $0.42 \pm 0.07^{\mathrm{a}}$ \\
SPM & $0.84 \pm 0.08^{\mathrm{b}}$ \\
CHA & $0.28 \pm 0.10^{\mathrm{c}}$ \\
DCHA & $0.52 \pm 0.24^{\mathrm{abc}}$ \\
CHA + SPM & $0.71 \pm 0.17^{\mathrm{b}}$ \\
DCHA + SPM & $1.45 \pm 0.57^{\mathrm{b}}$
\end{tabular}

Data are mean $\pm \operatorname{SE}(n=8)$. Values with different superscript letters are significantly different at $p=0.05$

cystocarps with ostiole. The highest levels of polyamines were found in samples at the second immature cystocarp stage. In Grateloupia (Sacramento et al. 2004), higher polyamine contents were observed in infertile than fertile collected samples. Further investigations in both species showed that polyamines, particularly spermine, promoted spore liberation and growth when added exogenously (Guzman-Urióstegui et al. 2002; Sacramento et al. 2004), thus revealing causal relation between the
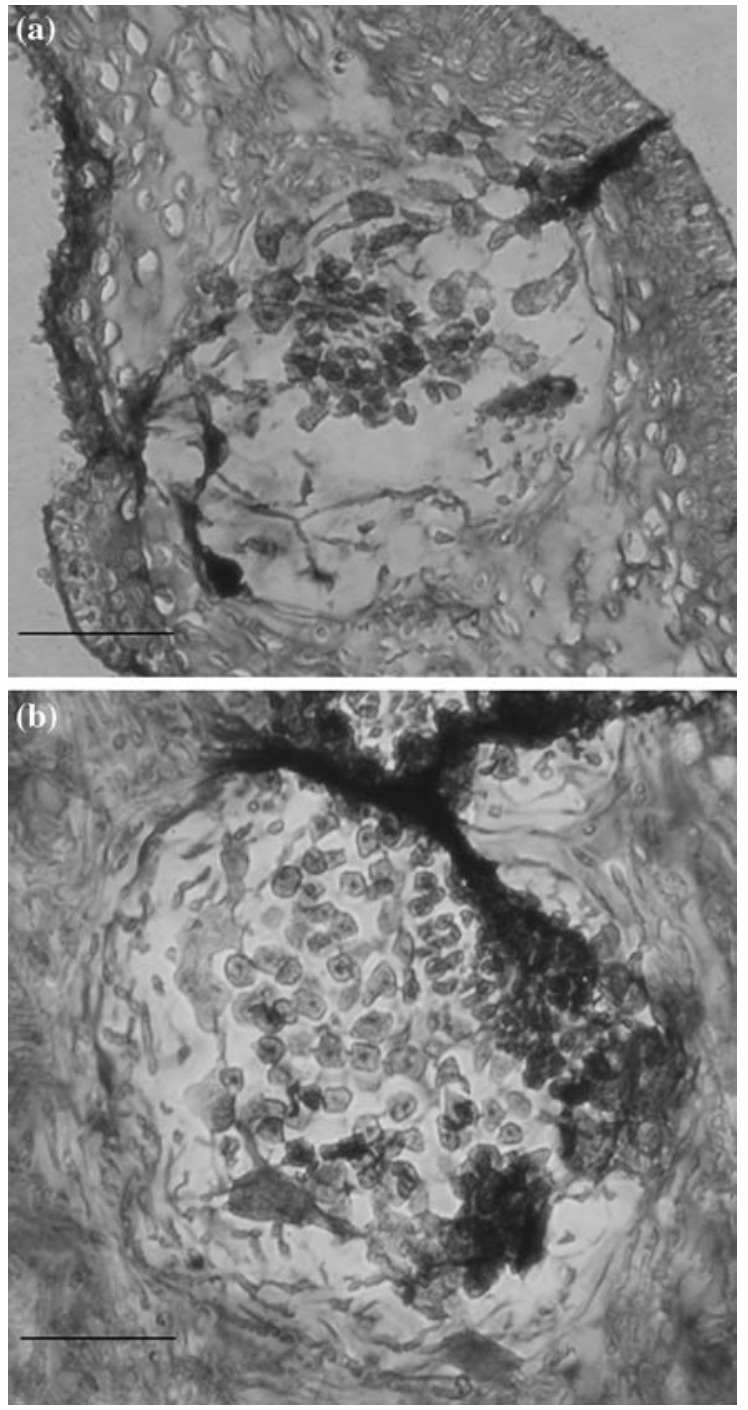

Fig. 2 Light micrographs of sections from explants of Grateloupia (a) cystocarp detected after 7 days in explants cultivated control PES for comparison to that developed in explants cultivated in spermine (b). Note profusely divided carpogonial branches and mature carposporangia. Scale bars: $120 \mu \mathrm{m}$

variation of polyamine content and the liberation of spores in this case.

In certain organisms, the differences in polyamine contents are not directly established, but they are the result of a characteristic pattern of changes which eventually have morphogenetic consequences in the reproductive processes. For example, in tomatoes, a constant level of endogenous spermine was observed in unpollinated and senescent ovaries, but decreased 
upon initiating parthenocarpic development as induced by treatment with $\mathrm{GA}_{3}$ or 2,4-D (Alabadí et al. 1996). Also in tomatoes, a sharp increase in spermidine and spermine preceded pollen germination (Song et al. 2001). However, the total polyamines increased with fruit development (Fos et al. 2003).

In this work, levels of polyamines were monitored in Grateloupia during the transition from infertile to fertile, which was possible through the cultivation of infertile axes from the same holdfast of fertilized individuals, and consequently assumed to be female. In Grateloupia, the cystocarp is developed in the auxiliary ampulla after the auxiliary cell receives the diploid nuclei from the fertilized carpogonial cell (De Clerk et al. 2005). Therefore, from the data in Table 1, we can conclude that the infertile axes had fertilized carpogonial cells, and thus developed cystocarps after a few days in culture. As one might expect, cystocarp development was not synchronous, so that the "population" of developing cytocarps increased progressively to reach its maximum differentiation by day 8 in culture. While the cystocarps were differentiating, the endogenous content of spermidine (Fig. 1) and, more strongly, spermine increased dramatically (25-fold) from days 0 to 5, and then decreased to the initial or even lower levels at day 8, when cystocarp development ceased. Putrescine did not mirror spermidine and spermine as it remained high and then decreased over day 5. It should be noted that the putrescine content in Grateloupia was over tenfold that of spermidine and spermine (Marián et al. 2000a, b; Sacramento et al. 2004). Therefore any minimal decrease, or even oscillation as seen between days 0 and 2 in Fig. 1, may explain a significant increase in the spermidine and spermine, since the synthesis of polyamines starts with putrescine. We can conclude from monitoring of endogenous contents of polyamines that, during the transition from infertile to fertile, the significant decrease in polyamine content is not directly established, as suggested when infertile and fertile samples of Grateloupia were compared (Sacramento et al. 2004). Spermidine and mainly spermine, the end-product of the metabolic pathway, are first accumulated until all of them (including putrescine which remained high), decreased abruptly. The results resemble those for other organisms, like tomatoes mentioned above, where a characteristic pattern of endogenous PA variations related to reproductive events has been observed. In the case of Grateloupia a strong accumulation of spermine and subsequent degradation preceded maximum cystocarp differentiation.

Enzymatic activities (Table 1) mirrored this pattern of PA accumulation, since the activity of ODC decreased during maturation, so that putrescine did not accumulate further until it was degraded, together with spermidine and spermine, due to the increase in oxidases. ODC is a ubiquitous enzyme related to cell division and growth, occurring during reproductive events in plants (Aribaud and Martin-Tanguy 1994; Alabadí et al. 1996; Galston et al. 1997). The decline in ODC activity in fertile thalli, compared to infertile thalli (Sacramento et al. 2004), together with the results obtained in this study support the hypothesis that ODC seems to be involved as it is regulated during the cystocarp development. In mammals, ODC is considered a key enzyme and is highly regulated, both transcriptionally and post-transcriptionally, even using a specific ubiquitin independent mechanism, with an antizyme (anti-enzyme) protein which is joined to ODC, for its degradation and rapid turnover (Hayashi et al. 1996). Rapid turnover has also been reported for ODC in plants and Chlamydomonas, but this appeared to be independent of the antizyme (Voigt et al. 2000; Lee and Cho 2001). In Grateloupia, we have observed that a semi-purified ODC preparation was active for 20 days and was inhibited by $\alpha$-difluoromethyl ornithine and spermidine, although the inhibition by spermine was much greater, up to $90 \%$ (Robaina, unpublished results). Consequently, the increase in free spermine showed in Fig. 1 may facilitate the control of ODC enzymatic activity. Feedback control of enzyme activities by polyamines has been previously described (Hiatt et al. 1986; Borrell et al. 1995; Theiss et al. 2002). Regarding the oxidative enzymes, DAO and PAO increase when there are high levels of polyamines, as well as being especially active in fast-growing tissue (Tang and Newton 2005; Paschalidis and RoubelakisAngelakis 2005; Delis et al. 2006), as may be expected during the production of carpospores.

The results in Table 2 also support an inductive effect of spermine on cystocarp development. Compared to the control, the treatment with CHA inhibited cystocarp development, reducing by over $50 \%$ the number of cystocarp spots in the explants. Spermine increased the number of cystocarp spots to 
double that in the control, and reversed the inhibitory effect of CHA. However the inhibitory effect of DCHA was not observed, thus its combination with spermine should be interpreted as being due to spermine alone. The structural changes illustrated in Fig. 2 provide further support for the induction of the cystocarp development by spermine. After 2 days, only the explants cultivated in spermine show the proliferation of microscopic cystocarps. These cystocarps were ready to form carpospores, and eventually produced conspicuous mature cystocarps after 7 days with a larger carpogonial development as compared to those in PES.

Spermine promoted liberation, growth and development of spores in Grateloupia (García-Jiménez et al. 1998; Sacramento et al. 2004) and, as discussed above, apparently induced the development of cystocarps, thus explaining its strong accumulation. Therefore this work focused on the effect of spermine, the apparently inductive agent. Previous results showing that putrescine inhibited the liberation of spores in Grateloupia (Sacramento et al. 2004) make rationale to think that it should not be accumulated during cystocarp development, which is consistent with the results obtained. The role played by spermidine remains elusive, since it proved to be inhibitory on spore liberation as putrescine (Sacramento et al. 2004), but accumulated like spermine the inductive agent of cystocarp development. To explain this dual situation, authors consider that the effects of polyamines are exerted by means of the relative ratios between polyamines (e.g. spermine/spermidine ratio), more than the particular endogenous level reached by one of them (Rey et al. 1994).

Another question to solve is how the alga regulates production and diffusion polyamine through the thallus cells to precise the time and the zone where the differentiation of cystocarps is going to occur. There are not evidences supporting the existence of polyamine transport mechanism in Grateloupia, to expect a systemic simultaneous sexuality in the thallus. In fact, cystocarp differentiation in Grateloupia is mostly located at the middle-distal part of the thalli in some axes arising from the same holdfast. It is suggested that gradients of polyamines could be established to precise the area of the thallus and the time of cystocarp differentiation.

In conclusion, the results suggest that, during cystocarp development, spermine is accumulated, thus favouring the development of cystocarps, given the presumed role of spermine as an inductor. Once this inductive effect is exerted, the excess of spermine is degraded by PAO.

Acknowledgements This work received the support of the Spanish Ministerio de Ciencia y Tecnología (BFI2003-01244). Likewise, we are grateful to the Autonomous Government of the Canary Islands for the scholarship awarded to Alicia Sacramento. We thank Prof. JA Raven for the critical review of this manuscript.

\section{References}

Alabadí D, Aguero M, Perez-Amador M, Carbonell J (1996) Arginase, arginine decarboxylase, ornithine decarboxylase and polyamines in tomato ovaries. Plant Physiol 112:1237-1244

Aribaud M, Martín-Tanguy J (1994) Polyamine metabolism in normal and sterile Chrysathemum morifolium. Phytochemistry 37:927-932

Badini L, Pistocchi R, Bagni N (1994) Polyamine transport in the seaweed Ulva rigida (Chlorophyta). J Phycol 30:599-605

Borrell A, Culiañez-Macia FA, Altabella T, Besford RT, Flores D, Tiburcio AF (1995) Arginine decarboxylase is localized in chloroplasts. Plant Physiol 109:771-776

Cohen E, Shoshana A, Heimer YH, Mizrahi Y (1984) Polyamine biosynthetic enzymes in the cell cycle of Chlorella. Plant Physiol 74:385-388

De Clerk O, Gavio B, Fredericq S, Bárbara I, Coppejans E (2005) Systematics of Grateloupia filicina (Halymeniaceae, Rhodophyta), based on rbcL sequence analyses and morphological evidence, including the reinstatement of $G$. minima and the description of $G$. capensis sp. nov. J Phycol 41:391-410

Delis C, Dimou M, Flemetakis E, Aivalakis G, Katinakis P (2006) A root and hypocotyls-specific gene coding for copper-containing amine oxidase is related to cell expansion in soybean seedlings. J Exp Bot 57:101-111

Flores HE (1990) Polyamines and plant stress. In: Flores HE (ed) Stress responses in plants: adaptation and acclimatation mechanism. Whiley-Liss, USA, pp 217-239

Fos M, Proaño K, Alabadí D, Nuez F, Carbonell J, GarciaMartinez JL (2003) Polyamine metabolism is altered in unpollinated parthenocarpic pat-2 tomato ovaries. Plant Physiol 131:359-366

Galston AW, Kaur-Sawhney R, Altabella T, Tiburcio AF (1997) Plant polyamines in reproductive activity and response to abiotic stress. Bot Acta 110:198-207

García-Jiménez P, Rodrigo M, Robaina R (1998) Influence of plant growth regulators, polyamines and glycerol interaction on growth and morphogenesis of carposporelings of Grateloupia cultured in vitro. J Appl Phycol 10:95-100

García-Jiménez P, Just MP, Delgado MA, Robaina RR (2007) Transglutaminase activity decrease during acclimation to hyposaline conditions in marine seaweed Grateloupia 
doryphora (Rhodphyta, Halymeniaceae). J Plant Physiol 364:367-370

Gavio B, Fredericq S (2002) Grateloupia turuturu (Halymeniaceae, Rhodophyta) is the correct name of the non-native species in the Atlantic known as Grateloupia doryphora. Eur J Phycol 37:349-359

Guzmán-Urióstegui A, García-Jiménez P, Marián FD, Robledo D, Robaina RR (2002) Polyamines influence maturation in reproductive structures of Gracilaria cornea (Gracilariales, Rhodophyta). J Phycol 38:1169-1175

Hayashi S, Murakami Y, Matsufuji S (1996) Ornithine decarboxylase antizyme: a novel type of regulatory protein. TIBS 21:27-30

Hiatt AC, Mcindoo J, Malmberg RL (1986) Regulation of polyamine biosynthesis in tobacco. $\mathrm{J}$ Biol Chem 261(3):1293-1298

Kakkar RK, Kaur-Sawhney V (2002) Polyamine research in plants- a changing perspective. Physiol Plant 116:281-292

Lee TM (1998) Investigations of some intertidal green macroalgae to hyposaline stress: detrimental role of putrescine under extreme hyposaline conditions. Plant Sci 138:1-8

Lee YS, Cho YD (2001) Identification of essential active sites residues in ornithine decarboxylase of Nicotiana glutinosa decarboxilating both L-ornithine and L-lysine. Biochem J 360:657-665

Marcé M, Brown DS, Capell T, Figueras X, Tiburcio AF (1995) Rapid high performance liquid chromatographic method for the quantitation of polyamines as their dansyl derivatives: application to plant and animal tissues. J Chromatogr B 666:329-335

Marián FD, García-Jiménez P, Robaina RR (2000a) Polyamine levels in the seagrass Cymodocea nodosa. Aquat Bot 68:179-184

Marián FD, García-Jiménez P, Robaina RR (2000b) Polyamines in marine macroalgae: levels of putrescine, spermidine and spermine in the thalli and changes in their concentration during glycerol-induced cell growth in vitro. Physiol Plant 110:530-534
Paschalidis KA, Roubelakis-Angelakis KA (2005) Sites and regulation of polyamine catabolism in the tobacco plant. Correlations with cell division/expansion, cell cycle progression, and vascular development. Plant Physiol 162:1297-1303

Provasoli L (1968) Media and prospects for the cultivation of marine algae. In: Watanabe A, Hattori A (eds) Cultures and collection of algae. Japanese Society of Plant Physiologists, Tokyo, pp 63-67

Rey M, Diaz-Sala C, Rodriguez R (1994) Comparison of endogenous polyamine content in hazel leaves and buds between the annual dormancy and flowering phases of growth. Physiol Plant 91:45-50

Sacramento AT, García-Jiménez P, Alcázar R, Tiburcio A, Robaina RR (2004) Influence of polyamines on the sporulation of Grateloupia (Halymeniaceae, Rhodophyta). J Phycol 50:887-894

Song J, Nada K, Tachibana S (2001) The early increase of S-adenosylmethionine decarboxylase activity is essential for the normal germination and tube growth in tomato (Lycopersicum sculentum Mill.). Plant Sci 161:507-515

Tang W, Newton RJ (2005) Polyamines promote root elongation and growth by increasing root cell division in regenerated Virginia pine (Pinus virginiana Mill.) plantlets. Plant Cell Rep 24:581-589

Theiss C, Bohley P, Voigt J (2002) Regulation by polyamines of ornithine decarboxylase activity and cell division in the unicellular green alga Chlamydomonas reinhardtii. Plant Physiol 128:1470-1479

Voigt J, Deinert B, Bohley P (2000) Subcellular localization and light dark control of ornithine decarboxylase in the unicellular green alga Chlamydomonas reinhardtii. Physiol Plant 108:353-360

Wallace HM, Fraser A, Hughes A (2004) A perspective of polyamine metabolism. Biochem J 376:1-14 